\title{
Investigation of Treatment Regimen of the Genital Warts Using Various Chemotherapeutic Agents
}

\author{
Arsalan Khan ${ }^{1}$, , Muhammad Jamil ${ }^{2}$, Rida $\mathrm{Naz}^{3}$, Ayesha Humayun ${ }^{4}$, Safi Ullah ${ }^{1}$, Ghulam Jelani ${ }^{5}$ \\ ${ }^{1}$ Livestock Research \& Development Station, Paharpur, Dera Ismail Khan, Pakistan \\ ${ }^{2}$ Arid Zone Research Centre, Pakistan Agriculture Research Council, Dera Ismail Khan, Pakistan \\ ${ }^{3}$ District Headquarter Teaching Hospital, Dera Ismail Khan, Pakistan \\ ${ }^{4}$ Department of Clinical Studies, Faculty of Veterinary and Animal Sciences, Arid Agriculture University, Rawalpindi, Pakistan \\ ${ }^{5}$ Department of Veterinary and Animal Sciences, University of Agriculture, Dera Ismail Khan, Pakistan
}

\section{Email address:}

drarsalankhandvm@gmail.com (A. Khan), jamilmatrah@gmail.com (M. Jamil), dr.ridaanaz@gmail.com (R. Naz), ayeshahumayun221@yahoo.com (A. Humayun), safugml@gmail.com (S. Ullah), drgjelani@gmail.com (G. Jelani)

${ }^{*}$ Corresponding author

\section{To cite this article:}

Arsalan Khan, Muhammad Jamil, Rida Naz, Ayesha Humayun, Safi Ullah, Ghulam Jelani. Investigation of Treatment Regimen of the Genital Warts Using Various Chemotherapeutic Agents. Biomedical Sciences. Vol. 6, No. 1, 2020, pp. 1-4. doi: 10.11648/j.bs.20200601.11

Received: October 28, 2019; Accepted: January 3, 2020; Published: January 21, 2020

\begin{abstract}
Genital warts are the most commonly sexually transmitted viral infection of human beings caused by Human Papillomavirus, infecting both male as well as female sexes. The disease is clinically characterized by the appearance of external warts on the genital organs viz penis, scrotum, vulva, anus and perineal area. The present study was designed for the investigation of chemotherapeutic agents for the successful treatment/removal of lesions of genital warts in terms of recovery of patients and clearance percentage of genital organs from the warts. For this purpose, a total of 12 patients infected with genital warts were selected and randomly distributed into four different groups, each group comprising 03 patients. Group A was treated using locally available wart removal preparation Dewart ${ }^{\circ}$ (Verrugon, Milk Acid), Group B was treated using Podophyllotoxin $15-25 \%$, procured from chemical suppliers, Group C was treated using locally available Duofilm ${ }^{\mathrm{TM}}$ (Salicylic Acid 16.7\% w/v, Lactic Acid 16.6\% w/v) and Group D served as negative control. The results of the current study revealed that the standard and most effective treatment of the genital warts is found to be Podophyllotoxin @15-25\%,which showed $100 \%$ recovery of the patients and $100 \%$ clearance of their genital areas from the stubborn warts. However, Duofilm ${ }^{\mathrm{TM}}$ was also found effective, because all the patients were recovered and $80 \%$ warts were cleared off from their genitalia, but after few weeks, the lesions re-appeared in the patients treated with Duofilm ${ }^{\mathrm{TM}}$. Also the warts did not go off with the local brands of Dewart ${ }^{\circledR}$ nor spontaneously recovered.
\end{abstract}

Keywords: Clearance Percentage, Dewart ${ }^{\circledR}$, Duofilm ${ }^{\mathrm{TM}}$, Genital Warts, Podophyllotoxin

\section{Introduction}

Genital warts, scientifically known as Condylomata acuminata, are the sequel of venereal diseases infecting large populations, even endemic in some zones of the world. The etiological agent of the disease, Human Papillomavirus (HPV), it is non-enveloped dsDNA virus with predilection site the epithelium of genital organs. It belongs to the viral family Papoviridae, which replicates in the basal layer of genital epithelium. Up till now 120 subtypes of HPV are discovered out of which, type $6,11,16,18,31,33$ and 35 are found responsible for clinical manifestation of genital warts (Figures $1 \& 2$ ), type 16, 18, 31, and 33 as high risk for 4 cervical cancers, while, HPV 6 and 11 are rarely known to cause cervical cancers but are responsible for $90 \%$ cases of genital warts $[1,2]$. It is known to be the direct cause of genital warts in both males and females. In males it only infects epithelium of genitalia, clinically characterized by visible warts, while, in females it is more hazardous causing genital warts as well as cervical cancer and anal [3, 4]. Human Papillomavirus is also potentially associated with ano-genital malignancy $[5,6]$. Its predilection site for 
infection is stratified and squamous epithelium. It propagates as warty growths on the skin of genitalia and manifest dysplastic cellular proliferations. Over 100subtypes of HPV are currently recognized, out of which 30 subtypes are found responsible for genital warts. Human Papillomavirus are also associated with neoplasia, while, type 6 and 16 are strictly associated with cervical cancer in females [7].

Genital warts are mostly transmitted through sexual contact with infected partner even close contact with the infected genitalia without intercourse, the disease may spread. Moreover, the infection may also be transmitted through non sexual routes including vertical transmission, colposcopes, transvaginal ultrasound probes, transplacental transmission, through saliva, digital contact, surgical instruments, infected needles or syringes, fomites etc [8]. These are clinically characterized by the warty outgrowth on the peri-genital and peri-anal anatomical locations [9, 10]. These are visible on external genitalia in the form of skin tags and lesions. Genital warts typically appear as flesh colored lesions on external genitalia and appear as small bumps on penis, scrotum, vulva, vagina, anus, pubic and perianal area, these may be flat or verrucous on the keratinized skin. Internal warts may also be produced in the vagina, cervix, urethra and even mouth [11].

For the purpose of screening of the disease, Papanicolau (Pap) test in developed countries is preferably used and FDA approved HPV vaccines Cervarix ${ }^{\circledR}$ (bivalent vaccine) is recommended which confers immunity against HPV types 16 and 18 , causing cervical cancers. The Cervarix ${ }^{\circledR}$ vaccine is used at the dosage schedule of 0,1 and 6 months @ $0.5 \mathrm{ml}$ intramuscular injection which gives immunity for 10 years [1].

As far as the therapy of genital warts is concerned, it particularly aims the elimination of the cutaneous lesions of warts rather than the elimination of underlying causative agent, HPV. However, for elimination of warts various topical treatment regimens are implied i.e. podophyllotoxin solution, imiquimod cream 5\%, Sinecatechinsointment $15 \%$ and podophyllin resin, with the clearance rate of $45-77 \%$, $13 \%, 58 \%$ and $42-50 \%$, respectively. Destructive or surgical implications for treatment include trichloroacetic acid $80-90 \%$ solution, cryotherapy (cold temperature induced dermal damages), electrocautery, scissor excision and carbon dioxide laser with the clearance rate of $70 \%, 79$ $88 \%, 94 \%, 72 \%$ and $23-52 \%$, respectively. Systemic treatment of the disease is based on interferons administration topically as well as systemically with the clearance rate of $17-67 \%[12-14]$. Commonly available vaccines for the prevention of genital warts are HPV2 Cervarix ${ }^{\circledR}$ (GlaxoSmithKline) and HPV4 Gardasil ${ }^{\circledR}$ (Merk and Co.) [6].

The main objective of the study was to investigate the chemotherapeutic agent for the treatment and removal of stubborn genital warts and to analyze the comparative efficacy of various chemical agents used under different brands for the treatment of the disease.

\section{Materials and Methods}

The experimental trial was conducted on the patients infected with genital warts which may reach the size of $10 \mathrm{~mm}$. The patients after clinical diagnosis were randomly distributed into four different groups, each group comprising 03 patients viz Group A, B, C and Group D (Table 1).

The patients in Group A were treated using locally available wart removal preparation Dewart ${ }^{\circledR}$ (Verrugon, Milk Acid), Group B was treated using Podophyllotoxin 15$25 \%$, procured from chemical suppliers, Group C was treated using locally available Duofilm ${ }^{\mathrm{TM}}$ (Salicylic Acid 16.7\% w/v, Lactic Acid 16.6\% w/v) and Group D served as negative control that whether the infection has spontaneous recovery or not. The chemical agents were used topically on the cutaneous warty lesions on the infected genital region using cotton buds or brush applicators, followed by washing with tap water after 4 hours of application the chemical, to minimize the systemic toxicity of the chemicals used. The treatment was continued till the complete elimination of the genital warts.

The locally available preparation Dewart ${ }^{\circledR}$ was applied topically on the genital warts twice daily for the period of 01 month, Podophyllotoxin $15-25 \%$ was applied topically on the warts once after every 3-5 days for the period of 01 month, Duofilm $^{\mathrm{TM}}$ was applied topically on the warts once after 5 days (from the site where wart was removed, wounds were produced and application of this preparation on the wound sites was prohibited, because it causes severe allergic reactions if applied directly on the wounds) for the period of 01 month, and the comparative efficacy of these chemicals was determined accordingly.

\section{Results \& Discussion}

The patients of Group A treated with Dewart ${ }^{\circledR}$ (Verrugon, Milk Acid) did not show any clearance of genital warts. The preparation may be used for the treatment of corns, skin or digital warts but did not give any successful results for the treatment of genital warts. All the patients were topically applied with the preparation continuously for the whole month but no success rate was found in Group A. Group B treated with Podophyllotoxin 15-25\%, showed $100 \%$ recovery and all the patients of Group B got rid of genital warts and their genitalia were cleared off without any complications. Our results are in agreement with the study in which it has been reported that the podophyllin (15-25\%) solution was the standard treatment for genital warts [13]. The podophyllin solution was applied twice daily for 3 days and thereafter rest of 4 days. Similar studies were also conducted in which they successfully treated the genital warts using podophyllin $15-25 \%$ solution $[9,14]$. Group C was treated using Duofilm ${ }^{\mathrm{TM}}$, all the three patients of the group showed $80 \%$ clearance rate with this preparation from genital warts. But after few weeks period the warty lesions reappeared in the patients of Group $\mathrm{C}$, on the same sites of infection. The patients in Group D did not show any 
clearance or recovery (Table 2). In related studies conducted for the eradication of genital warts, Ingenolmebutate and
Imiquimod $2-5 \%$ cream were used reporting $50 \%-80 \%$ warts clearance in the patients successfully $[15,16]$.

Table 1. Experimental Layout.

\begin{tabular}{lll}
\hline Group & Patient & Chemical used \\
\hline A & A1, A2, A3 & Dewart $($ Verrugon, Milk Acid) \\
B & B1, B2, B3 & Podophyllotoxin 15-25\% \\
C & C1, C2, C3 & Duofilm ${ }^{\mathrm{TM}}$ (Salicylic Acid 16.7\% w/v, Lactic Acid 16.6\% w/v) \\
D & D1, D2, D3 & Negative control \\
\hline
\end{tabular}

Table 2. Treatment regimens of various groups and their success rate in terms of recovery and clearance percentage of the patients.

\begin{tabular}{lllll}
\hline Group & Chemical used & Number of patients recovered & Clearance of each patient (\%) & Re-occurrence percentage (\%) \\
\hline A & Dewart $($ Verrugon, Milk Acid) & 0 out of $3(0 \%)$ & $0 \%$ & $100 \%$ \\
B & Podophyllotoxin 15-25\% & 3 out of $3(100 \%)$ & $100 \%$ & $0 \%$ \\
C & Duofilm ${ }^{\mathrm{TM}}$ (Salicylic Acid $16.7 \%$ & 3 out of $3(100 \%)$ & $100 \%$ & $80 \%$ \\
D & w/v, Lactic Acid 16.6\% w/v) & Negt of 3 $(0 \%)$ & $0 \%$ & $100 \%$ \\
\hline
\end{tabular}

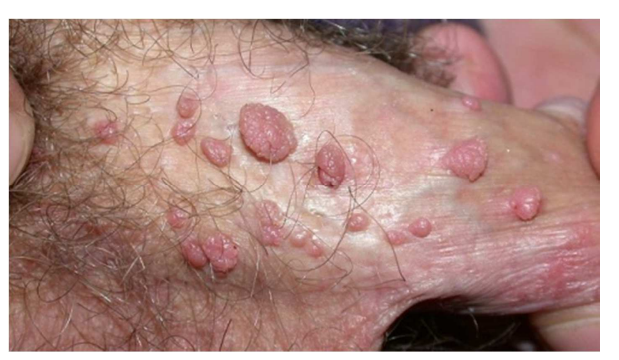

Figure 1. Clinical representation of genital warts on scrotum.

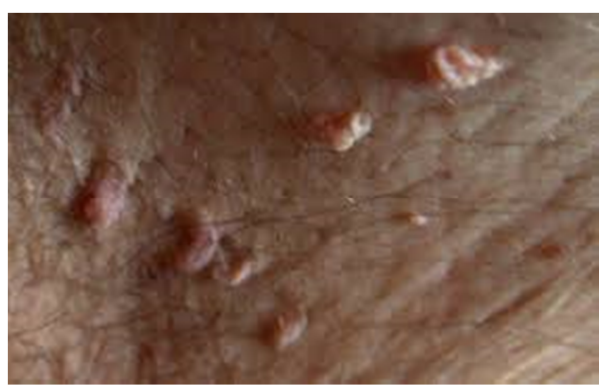

Figure 2. Clinical representation of genital warts on pubic area.

\section{Conclusion}

It has been concluded from this study that the most effective treatment of the genital warts is Podophyllotoxin (a) $15-25 \%$, with $100 \%$ recovery rate while other chemicals (Duofilm ${ }^{\mathrm{TM}}$ ) and local brands (Dewart $($ ) etc were ineffective for the treatment of genital warts and the lesions reappeared after few weeks of the treatment.

\section{References}

[1] Ghayas S, Anjum, F, HusainT, Bashir L, Naz S, Masood MA. Human Papillomavirus and its vaccine: Awareness and attitudes of young female Pakistani students. Khyber Med Univ J. 2018, 10 (4): 200-5.

[2] Scheinfeld N, Lehman DS. An evidence-based review of medical and surgical treatments of genital warts. Dermatol Online J. 2006; 12 (3): 5.
[3] Cates WJ. Estimates of the incidence and prevalence of sexually transmitted diseases in the United States. Sexually Trans Dis. 1999; 26 (4): 2-7.

[4] Markowitz LE, Dunne EF, Saraiya M, Lawson HW, Chesson $\mathrm{H}$, Hunger ER. Quadrivalent human Papillomavirus vaccine: Recommendations of the Advisory Committee on Immunization Practices (ACIP). Recommendations and Reports. 2007; 56 (2): 1-24.

[5] Walboomers JM, Jacobs MV, Manos MM, Bosch FX, Kummer JA, Shah KV, Snijders PJ, Peto J, Meijer CJ, Munoz N. Human Papillomavirus is a necessary cause of invasive cervical cancer worldwide. J Pathol. 1999; 189 (1): $12-19$.

[6] Valerie R, Rita Y, Patel V, Goldenberg G. Genital Warts A Comprehensive Review. J Clin Aesthet Dermatol. 2018; 5 (6): 25-36.

[7] deVilliers EM. Human Papillomavirus: Introduction. Seminars in Cancer Biology, 1999; 9 (6): 377.

[8] Sabeena S, Bhat P, Kamath V, Arunkumar G. Possible nonsexual modes of transmission of human papilloma virus. J Obstet Gynec Res. 2017; 43 (3): 429-435.

[9] Beutner KR, Wiley DJ, Douglas JM, Tyring SK, Fife K, Trofatter K, Stone KM. Genital warts and their treatment. Clin Infec Dis. 1999; 28 (1): 37-56.

[10] Munoz N, Bosch FX, Sanjose S, Herrero R, Castellsague X, Shah KV. Epidemiological Classification of human Papillomavirus types associated with cervical cancer. The New England J Med. 2003; 348 (6): 518-527.

[11] Batteiger BE. External genital warts. Best Pract. Med. 2000; 9 (10): 312-314.

[12] Yanofsky VR, Patel RV, Goldenberg G. Genital Warts: A Comprehensive Review. J Clinic Aesthetic Dermatol. 2012; 5 (6): 25-36.

[13] Charles M, Kodner MD, Nasraty S. Management of genital warts. J American Family Physician, 2004; 70 (12): 23352342 .

[14] Wiley DJ, Douglas J, Beutner K, Cox T, Fife K, Moscicki AB, Fukumoto L. External Genital Warts: Diagnosis, Treatment and Prevention. J Clinic Infect Dis. 2002; 35 (2): 210-224. 
[15] Reinholz M, Benjamin M, Engelshofen C, Heppt MV, Hirai Y Ruzicka T, Berking CV, Braunmühl TV. Successful Treatment of Genital Warts with Ingenol Mebutate Monitored with Optical Coherence Tomography and Reflectance Confocal Microscopy. Annals Dermatol. 2019; 31 (4): 434436.
[16] Moore RA, Edwards JE, Hopwood J, Hicks D. Imiquimod for the treatment of genital warts: A quantitative systematic review. BMC Infect Dis. 200; 1 (3): 1-9. 